\title{
Verzeichnis der Schriften zum Studium der Denkmalpflege.
}

I. Baden: Großherzogl. Badisches Ministerium der Justiz, des Kultus und Unterrichts, Instruktion für die Bezirkspfleger der Kunst- und Altertums-Denkmäler im Großherzogtum Baden. Karlsruhe 1899.

2. Der Burgwart. Zeitschrift. Berlin.

3. Clemen, Paul, Die Denkmalpflege in Frankreich. Berlin I 898 .

4. Die Denkmalpflege. Zeitschrift. Berlin.

5. Ebhardt, Bodo, Die Grundlagen der Erhaltung und Wiederherstellung deutscher Burgen. Berlin 190I.

6. Elsaß-Lothringen: Vorschriften der Dienstanweisung für die mit der Überwachung von aus Landesmitteln unterstützten Hochbauten der Gemeinden und Anstalten betrauten Baubeamten vom 21. Juni 190I, publiziert im Zentral- und Bezirks-Amtsblatt für Elsaß-Lothringen, Nr. 27 vom 29. Juni 1901 .

7. Frankreich: Rapport au ministre de l'intérieur. Monuments historiques. Paris $\mathbf{1 8 4 0}$.

8. Ministère d'État. Note, Circulaires et Rapports sur le service de la conservation des Monuments historiques. Paris $\mathbf{1} 862$.

9. Ministère de l'instruction publique, des cultes et des beaux-arts. Circulaires ministérielles relatives à la Commission des Monuments historiques. Liste des monuments classés. - Archives de la Commission. Paris 1875.

Io. Ministère de l'instruction publique et des beaux-arts. Loi et décrets relatifs à la conservation des monuments historiques. Paris 1900 . 
I1. Perrault-Dabot, A., Archiviste de la commission des monuments historiques au ministère de l'instruction publique et des beaux-arts. Les Archives de la Commission des Monuments historiques. Paris 1900.

12. Lörsch, Hugo, Das französische Gesetz vom 30. März I887. Ein Beitrag zum Recht der Denkmalpflege. Bonn.

13. Lutsch, H., Grundsätze für die Erhaltung und Instandsetzung älterer Kunstwerke geschichtlicher Zeit in der Provinz Schlesien. Berlin 1899.

14. Mielke, Robert, Museen und Sammlungen. Berlin 1903.

15. Näher, Julius, Die Burgen in Elsaß-Lothringen. 2 Hefte. Straßburg, im Kommission bei J. Noiriel 1886.

16. Näher, Julius, Die Burgenkunde für das Südwestdeutsche Gebiet. Anhang: Über die Mauertechnik und die Steinmetzzeichen bei den mittelalterlichen Burgenbauten. München 1901 .

17. Posse, Otto, Handschriften-Konservierung. Dresden 1899.

18. Preußen: Ministerium der geistlichen, Unterrichts- und Medizinal-Angelegenheiten. Merkbuch Altertümer aufzugraben und aufzubewahren. 2. Aufl. Berlin 1894.

19. Die formale Gestaltung der Kunstdenkmäler-Verzeichnisse der preußischen Provinzen. Berlin 1902. (Sonderabdruck aus der Zeitschrift: Die Denkmalpflege.)

20. Rathgen, Friedrich, Die Konservierung von Altertumsfunden. Berlin 1898 .

21. Reimers, J., Handbuch für die Denkmalpflege in Hannover. Hannover 1899.

22. Sachsen: Königlich Sächsische Kommission zur Erhaltung der Kunstdenkmäler. - Dresden, 1902.

I. Ratschläge für die Pflege kunstgewerblicher Altertümer von Holz, Metall, Elfenbein, Ton, Glas oder Textilstoffen.

2. Ratschläge zur Pflege von Öl- und Tempera-Gemälden.

3. Ratschläge für die Bewahrung und Erhaltung von alten Büchern und Einzelblättern. 
23. Schmid, Wolfgang Maria, Anleitung zur Denkmalspflege im Königreich Bayern. München I897.

24. Schweiz: Gesellschaft für Erhaltung historischer Denkmäler. Anleitung zur Erhaltung von Baudenkmälern und zu ihrer Wiederherstellung. Zürich 1893.

25. Tornow, Paul, Grundregeln und Grundsätze beim Restaurieren (Herstellen) von Baudenkmälern. Metz I902.

26. Winkler, C. u. Gutmann, K., Leitfaden zur Erkennung der heimischen Altertümer. Colmar I 894.

27. Wussow, A. von, Die Erhaltung der Denkmäler in den Kulturstaaten der Gegenwart. Berlin 1885. 2 Bände. 
